\title{
Considerações sobre uso de modelo construtivista no ensino de Engenharia: disciplina de projeto com graduandos e mestrandos
}

\author{
Fernando Schnaid* \\ Maria Isabel Timm** \\ Milton Zaro***
}

\begin{abstract}
Resumo: O artigo descreve e analisa uma experiência de aplicação do modelo construtivista de ensino-aprendizagem na Engenharia Civil, em aulas presenciais e a distância. Foi apoiada na hipermídia educacional composta de vídeos, livros, lâminas audiovisuais e outros recursos disponíveis em ambiente virtual, integradas a ferramentas de comunicação síncrona e assíncrona, material desenvolvido como parte de pesquisa realizada há cerca de dois anos pelo Núcleo de Multimídia e Ensino a Distância da Escola de Engenharia da Universidade Federal do Rio Grande do Sul. A experiência teve como base a formulação de Jean Piaget para o processo de aquisição do conhecimento, através da epistemologia genética, idéia que posiciona o aluno no centro do fenômeno educacional. Apresenta resumidamente esse conjunto de idéias e o material disponibilizado. e seu uso integrado às atividades propostas aos alunos. Analisa aspectos relevantes relacionados à implantação do modelo para atender necessidades específicas do ensino de conteúdos complexos e extensos, caso da Engenharia. Aponta para a continuidade da pesquisa, a partir da avaliação dos resultados.
\end{abstract}

\section{Apresentação}

A experiência foi aplicada no primeiro semestre letivo de $2002^{1}$, pelo professor Fernando Schnaid, na disciplina Ensaios Geotécnicos, do curso de graduação e mestrado em Engenharia Civil da Universidade Federal do Rio Grande do Sul/UFRGS. Teve como ponto de partida um projeto produzido pela doutoranda Maria Isabel Timm para a disciplina Fundamentos de Psicologia Cognitiva Aplicada à Informática Educacional I, do PGIE, sob orientação da professora Léa Fagundes. Foi realizada dentro do escopo das pesquisas sobre modelos didático-pedagógicos aplicáveis ao ensino de Engenharia, que vêm sendo desenvolvidas pelo Núcleo e deverá integrar atividade da linha de pesquisa proposta pelo mesmo grupo ao Programa de PósGraduação em Informática na Educação (PGIE) da UFRGS: Paradigmas para a pesquisa sobre o ensino científico e tecnológico.

\footnotetext{
*Engenheiro Civil, mestre pela PUC/RJ, PhD pela Oxford University, pesquisador do CNPq, coordenador do Laboratório de Engenharia Geotécnica e Geoambiental do Programa de Pós-Graduação em Engenharia Civil da UFRGS, fernando@ufrgs.br, http://nmead.ufrgs.br/fernando

**Jornalista, Especialista em Comunicação(PPGCOM-UFRGS),Doutoranda em Informática na Educação(UFRGS), Coordenadora Operacional do Núcleo de Multimídia e Ensino a Distância da Escola de Engenharia da UFRGS, betatimm@ufrgs.br, http://www.nmead.ufrgs.br/.

***Físico, Mestre em Física(UFRGS), doutor em Engenharia Mecânica(UFRGS), PhD em Metalurgia Física(UFSC), Coordenador Pedagógico do Núcleo de Multimídia e Ensino a Distância da Escola de Engenharia da UFRGS, zaro@ufrgs.br, http://www.nmead.ufrgs.br

${ }^{1}$ O projeto, propriamente dito, foi produzido ao longo do mês de maio/2002 e sua implantação ocorreu nos meses seguintes do mesmo ano, com a avaliação tendo sido realizada em setembro/2002. O trabalho da equipe com relação a essa disciplina, incluindo produção de material de multimídia e outras experiências pedagógicas implantadas, incluindo ensino a distância, já estavam sendo realizados desde 1999. 
Historicamente, o ensino de Engenharia Civil vem sendo feito, não apenas no Brasil, mas em todo o mundo, através da definição objetiva dos conteúdos e de sua transmissão, pelo professor, para os alunos. Nas décadas de 60 e 70, quando foram consolidados os currículos e modelos pedagógicos dos cursos de Engenharia atuais, o professor era a fonte prioritária de conhecimentos dos alunos, quando não a única. Bibliotecas e laboratórios foram sendo agregados, ao longo do tempo, como apoio ao ensino propriamente dito, que se passava, basicamente, dentro da sala de aula, sob responsabilidade quase que exclusivamente só do professor e dos livros. Esta é uma realidade em processo de intensa transformação.

Tomando-se por base as recomendações da ABET-Accreditation Board for Engineering and Technology, instituição norte-americana que procura estabelecer critérios de qualidade específicos para cada habilitação, os cursos de graduação devem estimular a capacidade para aplicar conhecimento de matemática, ciências e engenharia; projetar e conduzir experimentos; analisar e interpretar resultados; projetar um sistema, componente ou processo para atender a determinados requisitos; atuar em equipes multidisciplinares; identificar, formular e resolver problemas de engenharia; poder compreender a natureza da ética e da responsabilidade profissional; comunicar-se efetivamente (por escrito e oralmente); entender o impacto das soluções da engenharia no contexto social e ambiental; buscar a aprendizagem permanente; e ainda usar técnicas e ferramentas modernas para o exercício da prática da engenharia.

Publicações recentes, sobre o ensino de engenharia entre as quais Ludwig (2002), Bazzo (1998) e Becker (1999) analisam o tema pelo olhar do modelo pedagógico, referindo o esgotamento do chamado modelo positivista, identificado este conceito principalmente pela natureza da relação de transmissão-recepção de conteúdos entre o professor e o aluno, o qual seria apenas um elemento passivo no processo basicamente centrado na ação docente. A superação desse modelo estaria baseada sobre um novo enfoque pedagógico, focado no aluno, como sujeito do processo ensinoaprendizagem, no qual o professor seria um participante para mediar a ação do aluno sobre os conteúdos, uma ação portadora do processo de construção que o próprio aluno faz do seu conhecimento.

Este seria o modelo pedagógico construtivista, estabelecendo paradigmas de ensino capazes de dar conta da agregação dos referidos elementos necessários na formação do engenheiro: criatividade, sensibilidade, multidisciplinaridade e, sobretudo, estímulo à autonomia do aluno no seu próprio aprendizado. Trata-se de um modelo construído a partir da interpretação das déias do pesquisador suíço Jean Piaget, a respeito de como se desenvolve a aquisição de conhecimento, desde a primeira infância e ao longo de toda a vida dos indivíduos, tempo em que cada um iria construindo seu próprio universo de conhecimentos, pela sua própria ação sobre os possíveis objetos desse conhecimento.

A partir dessa análise, autores procuraram compreender os conceitos da epistemologia genética e definir um processo de trabalho, cuja primeira etapa constou da experiência relatada no presente trabalho. 


\section{Apropriação dos conceitos e contextualização}

Jean Piaget observou o desenvolvimento de crianças, desde o seu nascimento (Piaget, 1987), com objetivo de compreender os processos cognitivos envolvidos na aquisição de conhecimento pelos seres humanos, um tema recorrente entre os estudiosos do funcionamento dos processos mentais e, em especial, entre os pesquisadores da chamada psicologia cognitiva, que tratam de compreender os fenômenos da percepção, da aprendizagem, da memória e do raciocínio humanos. O objetivo dessa compreensão estaria exatamente na possibilidade de estimular a ocorrência, ou a velocidade ou a intensidade dos processos de aquisição de conhecimento, potencializando, dessa forma, o desenvolvimento dessas faculdades. No caso específico da aprendizagem, a compreensão do processo pelo qual os estudantes aprendem deve servir para orientar as ações dos educadores, levando-os a adotarem ações pedagógicas destinadas a estimular esse processo, através da criação de um ambiente educacional que reproduza as condições ótimas para que ocorra.

Piaget $(1987,1991,1997,2001)$ descreve o que chamou de epistemologia genética, ou a psicogênese do aprendizado: o processo mental através do qual o ser humano agrega novos conhecimentos, integrando-os ao conjunto de suas informações e vivências anteriores. Trata-se de um modelo dinâmico de funcionamento, baseado em um olhar que compõe as circunstâncias hereditárias (a biologia e a fisiologia que compõem o organismo humano) com a dinâmica vitalícia do próprio ser humano na construção de seu conhecimento. Para Piaget (1973), a natureza do que ocorre para viabilizar a cognição é semelhante ao que ocorre com as trocas orgânicas entre o corpo humano e o meio externo. O organismo tem necessidade de assimilar do ambiente (ar, alimento) e por isso age para se adaptar, aprendendo, com isso, a estruturar o ambiente na forma do que lhe é ou não conveniente, como, por exemplo, mamar ou não, respirar ou não). $O$ que no início obedece à lógica da ação pura e simples, através do relacionamento sensório-motor com o ambiente, irá se tornando mais complexo, à medida que as representações e operações mentais do indivíduo forem se tornando possíveis para mediar essa relação, sempre através de processos de assimilação, acomodação e organização dos novos esquemas no conjunto dos antigos esquemas. ${ }^{2}$

Segundo a interpretação pedagógica construtivista para o modelo de psicogênese da aprendizagem, de Piaget ${ }^{3}$, o aluno deve ser o sujeito do seu processo de aprendizagem. Para usufruir dessa condição, não pode apenas ficar sentado na classe anotando o que diz o professor. Deve sentir-se motivado pela curiosidade, realizando ações de exploração sobre objeto de estudo, uma postura que o levará a construir um acervo pessoal de conhecimento e não apenas aquele conjunto de informações que precisa dominar para passar na prova. Quanto à conduta do professor, o modelo não deve considerar-se como fonte principal de conhecimento à que o aluno terá acesso, mas o incentivador da busca do aluno em múltiplas fontes. Deverá perseguir o desenvolvimento de situações desafiadoras, para que o aluno movimente seus conhecimentos pré-existentes e perceba quais suas certezas e suas dúvidas sobre o tema, atuando para resolvê-las. Através de ações pedagógicas, o professor estará

\footnotetext{
${ }^{2}$ As obras referidas permitem o aprofundamento nas idéias de Piaget, que não será feito neste trabalho.

${ }^{3}$ Refere-se à interpretação construtivista porque Piaget pessoalmente não elaborou um modelo pedagógico, mas apenas fundamentou as idéias a respeito do processo de como se processa o aprendizado humano. 
problematizando o aluno, para que surjam as dúvidas que vão gerar o movimento de curiosidade do estudante e levá-lo a tomar consciência de qual conhecimento necessita.

Em resumo, o modelo construtivista parece configurar uma idéia de natureza não exatamente procedimental, mas uma postura sobre uma prática pedagógica, em permanente processo de autoconstrução, o que pode parecer (e pareceu, no caso apresentado) estranhamente subjetivo a professores de Engenharia, uma área do conhecimento marcada pela natureza prática, aplicativa e mensurável. Segundo Moraes (2000), a idéia é a de que o professor deve comprometer-se com o paradigma do construtivismo, e isso deve significar:

"adotar uma concepção de realidade em construção. E, em conseqüência, viver de acordo com isso, assumir atitudes construtivistas. É considerar-se permanentemente incompleto, inacabado e em constante construção”. (Moraes, 2000, p. 128)

\section{1 - Adequar as idéias à especificidade do ensino de Engenharia}

Dentro do processo de trabalho definido pela equipe, após a compreensão dos conceitos de Piaget e da interpretação de sua aplicação pelo modelo construtivista, essas idéias foram usadas para que a equipe para definir as condições da experiência, dentro da cultura educacional da Engenharia..

Aulas expositivas são a principal matriz de todo o processo educacional formal dos engenheiros, fortemente apoiadas em atividades práticas, sejam elas em laboratório (o que ocorreu a partir da década de 70 , quando a pós-graduação e a pesquisa em Engenharia começaram a ser estruturadas no País), sejam em extensas listas de exercícios, muitas vezes desconectados da prática profissional cotidiana do engenheiro, mas relacionados ao conteúdo proposto, usado como ferramenta de operação e fixação dos conteúdos teóricos. Essa prática, embora possa ser considerada obsoleta, enquanto modelo pedagógico, vem sendo mesclada, ao longo da última década, com atitudes mais flexíveis por parte dos professores, embora a percepção geral é a de que as aulas expositivas continuam sendo a principal estratégia pedagógica para ensinar engenharia.

Loder (2002), buscou identificar a prática pedagógica dos professores dessa área, tendo como base a observação e questionários realizados com alunos e professores de Engenharia Elétrica. Embora nenhum professor se declarasse formalmente construtivista, de um total de 11 observados apenas dois não incentivavam a participação dos alunos em aula. E o mesmo número deles teve práticas pedagógicas associadas pela pesquisadora como parcialmente construtivistas, em sala de aula. Este resultado foi um dos elementos usados pelos autores para refletir que, mesmo sem uma comprovação empírica, parece haver aspectos do ensino de Engenharia relacionados ao próprio saber envolvido nesta área, de natureza prioritariamente aplicável a situações práticas. Esta natureza prática de Engenharia seria por princípio incompatível com a falta de ação do aluno e poderia significar que, mesmo apresentando conteúdos de forma expositiva, em algum momento das aulas o professor é obrigado a lançar o aluno ao exercício prático daquele conteúdo, por si mesmo, reconhecendo suas dificuldades e superando-as, em função da própria exigência do curso.

Em uma tentativa de resumir de forma prática as etapas de implantação da experiência, foram definidos os seguintes itens: 
- identificar as estruturas mentais necessárias para a compreensão integral do conteúdo em pauta;

- identificar as etapas de assimilação, acomodação e organização dessas estruturas

- localizada essa cartografia de obstáculos, criar desafios nos quais o aluno :

- fique curioso pelo conteúdo;

- fique consciente do que sabe sobre o assunto (estruturas prévias) e das perguntas que terá de responder para saber mais (necessidade de conhecer);

- sinta-se motivado a pesquisar as soluções do desafio (agir sobre o objeto)

- realmente trabalhe sobre o novo tema (assimilação)

- aplique o que aprendeu, na solução do problema (acomodação, o novo conhecimento passa a fazer parte do banco de dados mental do aluno)

- faça um feed-back de todo o processo (organização).

\subsection{Condições definidas}

Extrapolando, talvez, a precisão conceitual da área da Educação, foi proposto pelos autores que o ensino de engenharia, pelas suas características, engendraria uma espécie de construtivismo modular, uma vez que cada unidade do conteúdo seria a estrutura cognitiva que o aluno deve assimilar, acomodar e organizar no conjunto de suas estruturas prévias. Esse tipo de construtivismo modular poderia ser definido, portanto, como um modelo pedagógico misto, peculiar ao ensino de Engenharia, no qual os alunos têm objetivos definidos (em cada módulo ou unidade do conteúdo), são expostos a alguma forma de acesso às informações (aulas expositivas ou pesquisa bibliográfica) e depois se lançam à utilização desse conteúdo, por conta própria, seja através de exercícios ou de práticas de laboratório. Optou-se, portanto, por uma formulação flexível. Não seriam dadas aulas expositivas como ponto de partida para a introdução aos assuntos, mas elas poderiam ocorrer, em momentos que o professor considerasse necessário, prioritariamente a partir das dúvidas e questões trazidas pelos alunos, depois que já tivessem tomado contato com o conteúdo, através do estudo dirigido e das mídias de apoio.

A exposição dos conteúdos deveria ser feita preferencialmente de forma dialogada com os alunos, alicerçada em interrogações ao próprio aluno, e ao grupo, solicitando o posicionamento dos alunos e do grupo sobre as soluções já encontradas. Além disso, esta exposição estaria fortemente apoiada no material de multimídia já existente: dois livros, uma série de cinco vídeos (em fita, na biblioteca), clipes sobre equipamentos disponíveis on-line, conjuntos de lâminas animadas com áudio, ambiente virtual com ferramentas de comunicação síncrona e assíncrona. O conjunto dos materiais está relatado em Schnaid et alli (2001).

\subsection{Auto-consciência, auto-avaliação e feed-back durante o processo}

Foi estabelecido que seriam propostos estudos dirigidos aos alunos, contendo questões a serem respondidas com o auxílio do material disponibilizado e através de discussões gerais e de grupos. Esses estudos dirigidos foram estruturados das unidades de conteúdo, as quais, para efeito de avaliação da experiência, foram consideradas pelo professor como as estruturas cognitivas que deveriam ser assimiladas e acomodadas 
pelos alunos. As etapas de assimilação e acomodação, dentro de cada um dos grandes itens, deveriam ser identificadas ao longo da observação ${ }^{4}$.

O processo de autoconsciência e auto-avaliação dos alunos deveria ser feito ao longo da resolução dos estudos dirigidos, em grupo, e nas reuniões de toda a turma, com base na observação do próprio professor, pela qualidade das participações orais, e na comparação com os resultados formais apresentados.

\section{2 - Desafios e interesse despertado pelo material de apoio}

O interesse pelos conteúdos foi estimulado através da solicitação para que cada grupo se estruturasse para emular a prática real de um projeto de engenharia de fundações, no caso o projeto de ampliação das obras do Aeroporto Internacional Salgado Filho, de Porto Alegre. Cada unidade-estrutura cognitiva deveria, portanto, ser estudada em relação a uma estrutura maior, desejável, na verdade, até mesmo em função do fato de que o curso de Engenharia Civil não trabalha com a execução de todas as etapas de um projeto real, que seria, dessa forma, realizado pela primeira vez pelos grupos. A aplicação final dos conteúdos aprendidos na forma de um projeto foi considerado o indicador da última etapa do processo cognitivo: acomodação e organização do novo conhecimento.

Para efeitos da avaliação da experiência, foram definidos alguns itens de observação, os quais foram examinados pelos alunos e pelo professor, ao final (resultados no item "Avaliações"):

- a participação dos alunos no conjunto das atividades;

- a consciência e a aceitação do grupo acerca da inovação pedagógica proposta;

- o nível de aquisição de conhecimento, em comparação a resultados de grupos anteriores da mesma disciplina;

- a eficiência do material de multimídia utilizado como acesso aos conteúdos;

- a testagem de linguagem de tecnologias educacionais inovadoras.

\section{4 - Implantação e observação da experiência}

A experiência ocorreu entre os meses de junho e setembro de 2002, com uma turma que juntou cerca de 25 alunos de graduação de Engenharia Civil e cerca de 15 alunos do Mestrado em Geotecnia. A integração entre alunos de níveis diferentes é uma prática já usada anteriormente, não tendo sido relacionada com a experiência pedagógica, considerando-se, entretanto, como um elemento positivo, por permitir aos graduandos o contato com alunos mais maduros e permitir aos mestrandos o exercício da atividade didática com colegas. Foram disponibilizados ao grupo os conteúdos em

\footnotetext{
${ }^{4}$ Este processo de observação não foi realizado na íntegra, devendo ter continuidade ao longo das próximas edições da experiência. 
multimídia da disciplina, através de web-site, dois livros, vídeos, apresentações audiovisuais de som e lâminas e planilhas com resultados de ensaios. O processo de observação do conjunto da experiência foi feito parcialmente pela doutoranda referida na apresentação deste trabalho, pelo próprio professor Fernando Schnaid, e por um dos alunos, mestrando ${ }^{5}$ que integra o grupo de pesquisa dos autores.

A primeira aula foi dada à distância, por vídeo, onde o Professor apresentou a disciplina e a idéia de inovação do processo pedagógico, relacionando-a à necessidade de autonomia no aprendizado, não apenas como uma demanda do curso, mas como uma prática necessária à atuação do engenheiro. Ao longo de cerca de 15 minutos de vídeo, foram apresentados detalhadamente os ambientes virtuais, os vídeos e o livro contendo as informações sobre o conteúdo proposto, como forma de apoio didático. Especificou os objetivos do curso (o projeto de engenharia geotécnica) e da aula daquele dia (o estudo dirigido que deveria ser discutido na aula seguinte); apresentou as mídias que teriam à disposição; as exigências de horário e, sobretudo, contextualizou a importância do aprendizado de projeto na prática profissional de Engenharia.

Esta forma de apresentação da disciplina cumpriu a função de surpreender e estimular a curiosidade dos alunos, pelo conteúdo e pela forma de abordagem. Foi responsável por: 1) sensibilizar o interesse do aluno, mobilizando sua curiosidade para a relevância da engenharia geotécnica; 2) disparar o processo, identificando-o como uma experiência pedagógica de estímulo ao auto-aprendizado, com base em material de multimídia pré-produzido; 3) apresentação do desafio, que seria caracterizado, no caso, pela exigência de execução de um projeto baseado em um caso de obra real; 4) orientar os alunos quanto ao nível de exigência, prazos e condições em que o trabalho seria executado.

\section{1 - Mudança na natureza dos encontros com o professor}

Ao longo dos encontros posteriores, os alunos chegaram à aula sempre com um trabalho realizado em grupo, com apoio no material de multimídia disponibilizado. Os alunos trabalharam em grupos e coletivamente, em aula. $\mathrm{O}$ ritmo do acesso ao material instrucional, conforme previsto no planejamento da experiência, foi definido pelos próprios alunos, bem como sua escolha de outras fontes. Assistiram aos vídeos individualmente ou em grupo, encaminhando dúvidas ao professor através de forum, chat ou até mesmo em telefonemas ao professor. $\mathrm{O}$ ambiente das aulas foi dedicado a prioritariamente a discussões sobre o conteúdo. A primeira consideração a esse respeito é a de que, em si, esta é uma postura inovadora em relação ao universo do ensino de engenharia, em que a prática comum é a de exposição de conteúdos seguida de exercícios. Além disso, há um ganho imediato na postura dos alunos, que não esperavam pelo professor para começar a estudar.

Os encontros, em geral, começavam com a pergunta do professor de "quem usou $o$ quê?", referindo-se ao material disponibilizado. Aos poucos, recebia questionamentos dos alunos sobre as dificuldades encontradas ao fazer o estudo dirigido. Muitas vezes o

\footnotetext{
5 Mestrando de Engenharia Civil Raymundo Carlos Machado Ferreira Filho, integrante do Núcleo de Multimídia e Ensino a Distância da Escola de Engenharia da UFRGS. Embora previsto no planejamento, não foram definidos indicadores capazes de quantificar o processo de evolução da experiência, tendo sido feita uma observação informal e relatos escritos dessa observação.
} 
professor remetia a dúvida dos alunos ao grupo e, em caso de respostas discrepantes, fazia uma espécie de votação entre, por exemplo, "sim", "não" e "talvez", surgidas no grupo. Nesses casos, o professor pautava as decisões remetendo a outras variáveis do projeto, e a conhecimentos anteriores, para justificar a tomada de decisão sobre uma ou outra resposta.

Também relacionava as dúvidas às questões ligadas ao fazer profissional. Por exemplo, ao sintetizar os itens que seriam necessários para o início de um projeto, supondo que os alunos tivessem sido contratados para o caso de obra proposto (ampliação do Aeroporto Internacional Salgado Filho, de Porto Alegre), o professor vai indagando quais os problemas que os alunos identificam. A primeira pergunta é: "No conjunto da obra, o que faz o engenheiro geotécnico?" O que se segue nessas situações seria um bom exemplo do chamado método socrático de extrair informações que fazem parte do conhecimento prévio do próprio aluno. A cada informação dos alunos, vai desenhando no quadro, por exemplo, a carga prevista para a estrutura. Nova pergunta: "Não precisa de água, luz, etc.?" A resposta dos alunos contém mais uma parte do que seria a utilização da infra-estrutura, com serviços, que precisam ser dimensionados. Nova pergunta: "O que eu preciso para projetar cada coisa dessas?" Resposta: aterro. Nova pergunta: o que é preciso saber sobre aterro? Resposta: a resistência do solo e recalque... Daí a importância da caracterização do aterro e a necessidade de estabelecer quais os possíveis problemas e quais os parâmetros de comportamento, informações que o equipamento em estudo naquele dia (SPT) pode fornecer.

Esse processo permite que os alunos se apropriem dos conceitos que já possuem e os relacionem com os novos conteúdos que estão sendo apresentados. Além disso, estabelece um feed-back em tempo real sobre o processo que o aluno está desenvolvendo, ao tomar consciência de todas as variáveis envolvidas no processo de construção de seu conhecimento sobre o tema, examinando inclusive possibilidades de decisões não adequadas. O objetivo dessa prática - que, na verdade, já fazia parte do cotidiano de trabalho do professor - é fazer com que o aluno aprenda a conscientizar dinamicamente todas as variáveis e sua inter-relação no conjunto do conteúdo, com base em questões práticas, que dimensionam a tomada de decisões do projeto.

\section{4 - Queixas contra "esse construtivismo"}

A experiência foi sendo encaminhada nos moldes dos exemplos que foram citados acima, com os alunos trabalhando em grupos, a partir dos estudos dirigidos propostos pelo professor a cada semana, com espaços coletivos para debate, esclarecimento de dúvidas e apresentação de conteúdos de forma variada, por vezes na forma de mídias, outras na forma de perguntas e respostas, outras na forma de exposição do professor ou dos próprios alunos (cada mestrando deveria se encarregar de uma aula). A rigor, esse andamento foi mantido sem traumas até que o grupo atingiu um determinado ponto do conjunto de conteúdos em que a exigência de conhecimentos teóricos é reconhecidamente maior. Especificamente, esse ponto foi atingido quando o grupo passou ao estudo dos Pressiômetros, cujo funcionamento exige conhecimento razoável de Teoria de Expansão de Cavidades, com uma matemática suficientemente complexa para exigir considerável dedicação, raciocínio e abstração.

Nesse momento, o grupo passou por uma compreensível turbulência, que foi atribuída, por alguns alunos, a "esse construtivismo" proposto. Durante o encontro do grupo, na semana em que deveriam ter realizado o estudo dirigido relacionado com 
Pressiômetros, os alunos iniciaram um debate em aula, cobrando aulas expositivas do professor. Em especial, uma aluna expressou insegurança e desconforto com o modelo não-convencional. A queixa da aluna: "Eu não fui educada em colégio construtivista, eu não quero modelo construtivista, eu quero aulas...”.

Curiosamente, o próprio grupo começou a debater as vantagens e desvantagens do modelo pedagógico adotado pelo professor. Um aluno referiu que "nunca aprendi tanto em todo o curso". Muitos, entretanto, disseram preferir esse sistema às aulas convencionais.

A interpretação dos autores para esse episódio relaciona-se à dificuldade do próprio conteúdo, especificamente naquele ponto da matéria onde a exigência do esforço era maior. Supõe-se que alguns alunos sentiram-se inseguros quanto à sua própria capacidade de compreender os conteúdos envolvidos, preferindo que o professor se encarregasse de destrinchar as complexidades, de forma a facilitar a compreensão. Este seria mais um dos argumentos a favor da montagem de modelos híbridos, tanto para evitar os desgastes da relação professor-aluno no processo de aprendizagem, quanto como forma de facilitar o contato dos alunos com conteúdos extremamente complexos. Sugere-se que o professor planeje seus cursos conhecendo de antemão esses momentos estratégicos (possivelmente os momentos de passagem à assimilação de novas estruturas cognitivas, como propôs Piaget), compondo para esses momentos um conjunto de exposições e de material de apoio, contendo inclusive revisão de conteúdos anteriores, se for o caso.

\section{5 - Avaliação da experiência: observações gerais}

Todas as apresentações dos trabalhos finais da disciplina, os projetos realizados sobre a obra do Aeroporto Internacional Salgado Filho, foram surpreendentemente corretas e seguras, sendo considerado pelo professor que todos os objetivos propostos do ponto de vista cognitivo foram atingidos por todos os grupos. Isso significa que:

- os alunos compreenderam o problema proposto (fazer um projeto);

- compreenderam os conhecimentos envolvidos no diagnóstico e solução desse problema (a visualização dos fenômenos físicos e a sua respectiva representação matemática), lançando-se à pesquisa daqueles que não faziam parte de seu repertório já existente de conhecimentos;

- integraram esse conjunto de conhecimentos em um cenário de interação das variáveis do problema e de suas possíveis soluções. Houve uma única desistência entre um grupo de aproximadamente 40 alunos.

Os trabalhos finais apresentados pelos grupos de alunos foram variados no seu conteúdo e na forma de abordagem da proposta feita pela disciplina, que era a de realização de um projeto completo da área de engenharia geotécnica, relacionado à obra de ampliação do Aeroporto Internacional Salgado Filho, em Porto Alegre. Alguns grupos realizaram exatamente essa atividade, dentro de suas múltiplas possibilidades de abordagem; outros realizaram projetos geotécnicos de outras obras, em outros locais; e outros ainda realizaram apenas os ensaios propostos para o diagnóstico do solo, ou compararam vários deles. Essas atividades, entretanto, foram acordadas com o professor, ao longo dos trabalhos feitos pelos alunos nos estudos dirigidos. Todos os grupos apresentaram resultados finais solidamente fundamentados na teoria, resultados precisos nas observações feitas para diagnosticar as condições do subsolo e, sobretudo uma sólida evidência de aplicação dos conteúdos tratados em aula, seja pelo domínio da 
linguagem, seja pela consistência das justificativas. Por razões óbvias, relacionadas à maturidade intelectual e à própria natureza do estudo de pós-graduação, os trabalhos dos alunos de mestrado apresentaram maior grau de aprofundamento nas justificativas e uma maior organização na forma final do relatório, com boa descrição de objetivos e metodologia de trabalho.

O mesmo cuidado com a precisão da linguagem e clareza de objetivos pôde ser observado durante as apresentações finais, feitas para todo o grupo. Sugere-se que a dinâmica das discussões feitas ao longo da disciplina serviu como exercício prático de segurança de expressão em grupo e comunicabilidade, habilidades descritas como desejáveis na prática da engenharia contemporânea, onde o trabalho se fundamenta em equipes. Os trabalhos foram apresentados oralmente, com apoio em lâminas eletrônicas (Power Point), que exigiram também dos grupos um planejamento de recursos de apoio a essa comunicação com o grupo, possivelmente também estimulados pelo ambiente multimídia que cercou o conjunto da experiência, durante todo o tempo.

\section{1 - Avaliação pelo professor}

Foi feita uma avaliação qualitativa, com base na opinião do professor, e foram distribuídos questionários aos alunos, com itens relacionados à comparação da experiência com aulas convencionais, a compreensão dos conteúdos, à participação nas atividades propostas. $\mathrm{O}$ conjunto de observações a seguir foi produzido a partir das avaliações pessoais do professor.

5.1.1 - Perguntas freqüientes: Algumas perguntas comuns em outros anos não apareceram desta vez, ou pelo menos não com a mesma freqüência de anos anteriores. A interpretação para isso foi a de que os alunos, ao fazer uso do material de apoio disponibilizado, que inclui uma sessão de perguntas freqüentes, se viu induzido a refletir sobre as questões, previamente às aulas de discussão. Deve-se ainda salientar que, entre os alunos de Mestrado, que tiveram uma aula semanal a mais, as perguntas foram de nível mais aprofundado. 
5.1.2 - Aquisição de conteúdo - Não houve prejuízo em relação aos resultados encontrados em outros anos. Todos os alunos atingiram um nível mínimo desejável à aprovação. 
5.1.3 - Domínio do jargão técnico - Nas primeiras aulas, os alunos não conseguiam usar a linguagem técnica. Ao longo da disciplina, demonstraram um perceptível amadurecimento no uso e na familiaridade com os termos técnicos relativos aos conteúdos da disciplina.

5.1.4 - Dinâmica do aprendizado - Os alunos foram colocados em diferentes situações. A situação de apresentação formal dos conteúdos deveria ocorrer na forma de solução das dúvidas geradas pelo estudo dirigido entregue na semana anterior, uma forma não usual no ensino de Engenharia Civil da UFRGS. Nem todos os alunos, principalmente os da graduação, identificaram esse momento como de apresentação de conteúdos e, durante esses encontros gerais, houve manifestações de descontentamento com o que seria uma nova cultura de aprendizado autônomo, não conhecida e não desejada. Sugere-se que modelos puramente construtivistas sejam mais eficientes com alunos maduros. Quanto à complementação da apresentação de conteúdos através do material disponibilizado (web-site, vídeos, livros), todos os alunos realizaram esse momento do aprendizado. Não houve casos de alunos que tenham deixado de responder ou que tenham referido não acessar o material. Também buscaram outras fontes diferentes daquelas ofertadas pelo professor, como por exemplo, a consulta a alunos de doutorado. As aulas de discussão, que ocorreram só para os alunos de Mestrado, apresentaram um alto nível de crítica dos assuntos tratados e também propiciaram o surgimento de assuntos paralelos. Foram o ambiente de maior troca, apesar de que os alunos, quando chegavam à aula, estavam estressados em função das dificuldades encontradas para o domínio básico dos conteúdos. Ao longo da aula havia muita participação e ao final mostravam alívio e claro entendimento dos fundamentos teóricos colocados.

5.1.6 Relato de comportamento específico - A mobilização dos alunos foi surpreendente. Mesmo com a carga de estudos extremamente exigente, todos se mobilizaram, nenhum reclamou do excesso de demanda e alguns inclusive telefonaram em finais de semana, o que não é habitual (nem desejável). Também houve inúmeras mensagens enviadas por e-mail. Além disso, os alunos se apoiaram muito em alunos do doutorado, o que demonstra que procuraram fontes de informação e solução de dúvidas além do professor e do material disponibilizado.

\section{2 - Avaliações feitas pelos alunos}

Foram distribuídos dois questionários, um para os alunos de Mestrado e outro para alunos de graduação, com itens relacionados aos itens definidos anteriormente para avaliação. Também houve um espaço da avaliação dedicado a opiniões pessoais, em cada item e no geral de pontos positivos e negativos da experiência.

Foram devolvidos dez questionários respondidos por alunos de graduação e 18 por mestrandos. Os resultados serão apresentados por tema e por grupos específicos de alunos, em tabela integrada.

\section{6..2.1 - Material disponibilizado}

A avaliação do material foi considerada importante para a elaboração de novas edições da experiência, uma vez que os autores identificam a disponibilização de material formatado adequadamente em múltiplas mídias como essencial à qualidade de 
cursos, presenciais e a distância, na área tecnológica. $(\mathrm{G}=$ Graduação $\mathrm{M}=$ Mestrado Para todas as tabelas)

\begin{tabular}{|c|c|c|c|c|c|c|c|c|c|c|c|}
\hline & \multicolumn{2}{|c|}{ Ótimo } & \multicolumn{2}{|c|}{ Bom } & \multicolumn{2}{|c|}{ Médio } & \multicolumn{2}{|c|}{ Ruim } & \multicolumn{2}{|c|}{ Nãousou } & Inadequado \\
\hline & $G$ & M & G & $\mathbf{M}$ & G & $\mathbf{M}$ & G & M & $\mathbf{G}$ & $\mathbf{M}$ & M \\
\hline Vídeos & 4 & 7 & 4 & 5 & & 1 & 1 & & & 2 & \\
\hline Web-site & 4 & 12 & 5 & 6 & 1 & & & & & & \\
\hline Livro & 3 & 12 & 5 & 5 & 1 & 1 & 1 & & & & \\
\hline \begin{tabular}{ll|}
$\begin{array}{l}\text { Aula } \\
\text { vídeo }\end{array}$ & em \\
\end{tabular} & 2 & 8 & 2 & 9 & 5 & & & & 1 & & 1 \\
\hline
\end{tabular}

\section{A - Alunos de graduação}

A aula em vídeo, compreensivamente, foi o material mais controvertido: dois alunos consideraram ótima; dois alunos consideraram um bom material; cinco alunos consideraram que foi médio; e um aluno não usou (possivelmente por não ter estado em aula). Os vídeos foram considerados ótimos por quatro alunos; bons por outros quatro; ruim por um aluno e não foi usado também por apenas um aluno. O web-site foi considerado ótimo por quatro alunos; bom por cinco alunos; e médio por um aluno. Nenhum aluno considerou-o ruim e também não houve referência de não terem usado. Os livros foram considerados ótimos por três alunos; bons por cinco alunos, médio por um aluno; e ruim por um aluno. Não houve informação de aluno que não houvesse usado os livros indicados.

Nas opiniões pessoais sobre esse item, houve uma reclamação sobre um vídeo que estava disponibilizado na biblioteca e não funcionou, outra a respeito da manipulação do site (interpretada como navegabilidade). E uma opinião ressaltando que a utilização de tecnologia estimula os alunos a utilizarem métodos mais avançados.

\section{B - Alunos de mestrado}

Como entre os graduandos, a aula em vídeo foi o único material que teve uma indicação completamente negativa, como inadequado. Em compensação, foi muito maior a proporção de alunos que respondeu a essa situação de forma entusiasmada: oito alunos disseram que o material estava ótimo, e nove consideraram que estava bom. Lembrando-se que um bom número de alunos de graduação considerou que foi uma solução média, supõe-se que os alunos de mestrado já estejam mais maduros e, portanto, têm um perfil mais compatível com uma solução do tipo aula a distância, sem a presença física do professor. A mesma justificativa pode ser dada ao fato de que os livros e o site foram os mais citados na preferência desses alunos (12 respostas ótimo para cada um; seis respostas bom para o site; cinco para o livro; nenhuma para médio ou ruim). Possivelmente, o livro e o site na Internet foram as principais fontes de pesquisa dos alunos de mestrado.

A interpretação geral da resposta dos alunos é a de que o material disponibilizado foi satisfatório, útil ao auto-aprendizado e estimulante aos alunos. 


\subsection{2 - Conteúdos: compreensão/participação}

\begin{tabular}{|c|c|c|}
\hline & $\begin{array}{l}\text { Em relação às aulas } \\
\text { convencionais, aprendeu } \\
\text { Graduação Mestrado }\end{array}$ & $\begin{array}{l}\text { Em relação às aulas } \\
\text { convencionais, participou } \\
\text { Graduação Mestrado }\end{array}$ \\
\hline Muito mais & 5 & 4 \\
\hline Mais & 11 & 12 \\
\hline Menos & 1 & 3 \\
\hline Muito menos & & 1 \\
\hline
\end{tabular}

\section{A - Alunos de graduação}

Esse item da avaliação procurou detectar a percepção do aluno sobre sua própria experiência de aprendizado. As respostas dos alunos de graduação indicam que nove alunos (em dez) consideram ter aprendido mais na experiência construtivista, em relação às aulas convencionais. Apenas um indica ter aprendido menos. Também em comparação com as aulas convencionais, quatro alunos consideraram ter participado muito mais; três disseram ter participa do mais; e três responderam ter participado menos.

\section{B - Alunos de mestrado}

Entre os alunos de mestrado, cinco relataram ter aprendido muito mais, enquanto 11 informaram ter aprendido mais e apenas um disse ter aprendido menos. Esta é uma resposta bastante eloqüente em relação à consciência de alunos maduros sobre seu processo de aprendizagem. Talvez deva ser lembrado, entretanto, que os mestrandos tiveram um encontro semanal a mais do que os graduandos. Também é eloqüente a informação de que 12 alunos disseram ter participado mais dessas aulas do que das aulas convencionais, e quatro disseram ter participado muito mais. Um único aluno disse ter participado muito menos (possivelmente o que disse ter aprendido menos). Considerou-se que a grande maioria dos alunos aprendeu e participou mais dos encontros relacionados à experiência construtivista do que em relação às aulas convencionais. Além disso, a interpretação dessas respostas indica que todos perceberam que existia uma diferença de natureza no processo pedagógico proposto.

Nas manifestações pessoais relacionadas a esse item, alguns alunos de graduação citaram a diferença entre o grande grupo (considerado "muita gente em aula") e o trabalho em pequenos grupos, tendo sido citada essa última situação como uma experiência prática da dificuldade de obter consenso entre o grupo. Estas opiniões remetem para a avaliação do professor, de que a experiência com modelos pedagógicos dessa natureza seriam mais eficazes com grupos pequenos. $\underline{\mathrm{O} \text { espaço de trabalho em }}$ pequenos grupos é capaz de favorecer o intercâmbio de idéias e de vivências mais semelhantes ao exercício profissional.

Já entre os alunos do mestrado, houve seis manifestações pessoais sobre esse item, a maioria das quais (quatro) referentes à natureza das aulas expositivas ou não, o que dá uma boa dimensão da importância desse assunto, mesmo para alunos maduros. Um deles, inclusive, citou exatamente o momento do trabalho em que foi preciso uma aula que chamou "formal", porque o conteúdo era muito difícil para ser dominado 
individualmente. Trata-se exatamente do estudo sobre Pressiômetro, citado anteriormente na observação da experiência, como sendo o momento em que alguns alunos reclamaram do construtivismo. Uma outra opinião corrobora a opinião dos autores, para refletir sobre esses casos: 'Mesmo com uma maior participação no tipo de aulas dadas, não se exclui a necessidade de ter-se aulas do tipo convencional”. Outra manifestação de aluno dá conta da importância do auto-aprendizado: "As aulas expositivas não são tão produtivas quanto as aulas desta disciplina. Quando os problemas são colocados em nossa mão para serem resolvidos, nos obrigamos a buscar soluções, adquirindo conhecimento e experiência". Na verdade, ambos os modelos expositivo e auto-construído - de apresentação de conteúdos contêm vantagens e desvantagens, podendo, segundo parece no momento aos autores, ser integrados, em favor de uma maior eficiência.

\subsection{3 - Aprendizagem - dúvidas}

Esse item é um dos casos em que os alunos assinalaram mais de uma resposta no questionário, o que dá uma boa idéia da percepção dos vários momentos do processo de aprendizagem e do tipo de aproveitamento de cada um, tanto entre os alunos de graduação como de pós-graduação. Além disso, percebe-se também que a integração entre o grupo foi tão importante quanto a participação do professor, uma vez que houve um bom número de respostas sobre resolução de dúvidas para um e outro item. Vale ressaltar que a integração do grupo é um item desejável no processo de aprendizagem, tanto por caracterizar uma natureza colaborativa da educação construtivista, como por atender ao perfil do engenheiro do século XXI, o qual, entre outras características, deve aprender a trabalhar em equipe.

\begin{tabular}{|c|c|c|}
\hline & Graduação & Mestrado \\
\hline $\begin{array}{l}\text { Foram bem resolvidas pelo prof. } \\
\text { Fernando }\end{array}$ & 8 & 14 \\
\hline Foram resolvidas pelos colegas & 8 & 10 \\
\hline Foram resolvidas nos estudos dirigidos & 5 & 11 \\
\hline Foram resolvidas no Fórum & & 3 \\
\hline Foram mal resolvidas & 1 & 1 \\
\hline Não foram resolvidas & & \\
\hline
\end{tabular}

\section{A - Alunos de graduação}

Apenas um aluno de graduação informou que suas dúvidas foram mal resolvidas ao longo da disciplina. Oito consideraram que foram resolvidas pelo professor, oito pelos colegas e cinco alunos disseram ter suas dúvidas resolvidas nos estudos dirigidos.

Nas opiniões pessoais, foi referido que as dúvidas surgiram durante a realização dos estudos dirigidos e resolvidas com os professores e colegas. Essa opinião confirma a identificação, pelo aluno, de momentos diferenciados, ao longo do processo de aprendizagem, conforme estabelecido na proposta.

\section{B - Alunos de mestrado}


O grupo de mestrandos teve um encontro semanal a mais, para debater dúvidas, o que foi considerado pelo professor um momento privilegiado para que ocorressem debates de alto nível sobre os temas dos estudos dirigidos. Esse fato justifica, possivelmente, a grande maioria de respostas sobre os momentos em que foram resolvidas: pelo professor (14); pelos colegas (10); através dos estudos dirigidos (11); e no Fórum (3), sendo esse último o espaço no site dedicado à discussão dos temas propostos em aula (vale lembrar que nenhum alunos de graduação disse ter solucionado dúvidas nesse ambiente). Todas as perguntas são compatíveis com o perfil do aluno de pós-graduação, cujo objetivo do estudo está mais focalizado na aprendizagem do que nas exigências feitas em aula. Apenas um aluno de mestrado respondeu que as dúvidas foram mal resolvidas, possivelmente o mesmo que, nas manifestações pessoais, queixou-se de que o professor poderia ser mais acessível.

Outras opiniões sobre esse item relacionam o fato de que os estudos dirigidos levantavam dúvidas, as quais eram resolvidas em qualquer um dos outros momentos de interação, pelo professor ou junto aos colegas.

\subsection{4 - Aprendizagem: estilo}

\begin{tabular}{|l|cc|}
\hline $\begin{array}{l}\text { Quando e onde lembra de ter aprendido } \\
\text { mais? }\end{array}$ & Graduação & Mestrado \\
\hline $\begin{array}{l}\text { No contato individual com o material de } \\
\text { apoio }\end{array}$ & 3 & 6 \\
\hline Na procura de outras fontes de pesquisa & 3 & 1 \\
\hline $\begin{array}{l}\text { Nas aulas de solução de dúvidas com o } \\
\text { grupo todo }\end{array}$ & 3 & 5 \\
\hline $\begin{array}{l}\text { Nas "rodas" de solução de dúvidas só do } \\
\text { mestrado }\end{array}$ & & 14 \\
\hline $\begin{array}{l}\text { Durante a execução do trabalho, com seu } \\
\text { grupo }\end{array}$ & 4 & 6 \\
\hline Preparando e dando aulas ao grupo & & \\
\hline
\end{tabular}

\section{A) Alunos de graduação}

Quatro alunos indicaram os trabalhos de grupo, fortalecendo a hipótese levantada no item anterior, de que o trabalho estimulou a integração do grupo e o espírito de equipe. Os seguintes receberam três indicações cada um: no contato individual com o material de apoio; na procura de outras fontes de pesquisa; nas aulas de soluções de dúvidas com o grupo todo.

\section{B) Alunos de mestrado}

Entre os mestrandos, o estilo campeão da preferência da maioria (14 respostas) foram as chamadas "rodas de solucão de problemas", que ocorreram nos encontros semanais extraordinários, o que fortalece a idéia levantada pelo professor, em sua própria avaliação, de que grupos menores são mais indicados para experiências dessa natureza. Infelizmente, estas evidências colidem, hoje, com as políticas públicas de massificação do ensino superior, com aumento sistemático do número de vagas e 
redução do número de professores. Além dessa forma, os alunos também citaram o estudo individual do material de apoio (seis respostas), a execução do trabalho em grupo (seis respostas) e as aulas de solução de dúvidas com o grande grupo (cinco respostas). Apenas um aluno indicou a busca de outras fontes de pesquisa, possivelmente o mesmo que, nas opiniões pessoais, disse ter buscado soluções individuais, o que parece indicar que o grupo do mestrado teve uma intensa interatividade interna.

Os comentários pessoais referem basicamente a importância da interação entre todas as formas de aprendizagem. Uma resposta, em especial, praticamente resumem a conscientização do aluno sobre o pressuposto construtivista de aprendizagem: 'Quando o aluno realmente está pesquisando, procurando solucionar suas dúvidas, pesquisando na bibliografia, é quando se aprende efetivamente". Relembrando, Piaget enfatiza exatamente que o aprendizado ocorre quando o indivíduo age sobre seu objeto de estudo, o que, em outras palavras, é o que disse o aluno.

\subsection{5 - Aprendizagem: domínio de linguagem}

\begin{tabular}{|l|lc|}
\hline & $\begin{array}{l}\text { Em que momento sentiu-se seguro de } \\
\text { dominar a linguagem técnica? } \\
\text { Graduação }\end{array}$ \\
\hline $\begin{array}{l}\text { No contato individual com o material de } \\
\text { apoio }\end{array}$ & 5 & 9 \\
\hline Na procura de outras fontes de pesquisa & 2 & 3 \\
\hline $\begin{array}{l}\text { Nas aulas de solução de dúvidas com o } \\
\text { grupo todo }\end{array}$ & 1 & 4 \\
\hline $\begin{array}{l}\text { Nas “rodas" de solução de dúvidas só do } \\
\text { mestrado }\end{array}$ & & 8 \\
\hline $\begin{array}{l}\text { Durante a execução do trabalho, com } \\
\text { seu grupo }\end{array}$ & 4 & 9 \\
\hline Preparando e dando aulas ao grupo & & \\
\hline
\end{tabular}

\section{A - Alunos de graduação}

Cinco alunos de graduação indicaram ter dominado a linguagem técnica durante o contato individual com o material de apoio, o que permite supor que houve boa compreensão dos conteúdos disponibilizados através de múltiplas mídias, bem como que a linguagem usada nas mídias foi adequada e acessível, servindo como apoio eficiente ao processo de aprendizagem dos alunos. Quatro alunos disseram ter dominado a linguagem técnica durante a execução dos trabalhos em grupo, o que confirma ainda a suposição feita nos itens anteriores, relativa ao estímulo da colaboração. Dois alunos referiram a procura de outras fontes de pesquisa como o momento de domínio de linguagem e apenas um aluno referiu o momento das aulas com o grupo completo, o que sugere que as aulas expositivas realmente não são bons instrumentos para estimular o domínio de linguagem técnica.

\section{B - Alunos de mestrado}


Também nesse grupo, uma grande parte dos alunos (nove) indicou ter dominado a linguagem técnica no contato individual com o material de apoio, fortalecendo a interpretação já referida acima. O mesmo número de alunos indicou também o trabalho em pequeno grupo; e oito alunos indicaram a "roda de solução de problemas". Também foram referidos o grupo todo (quatro respostas) e a busca de outras fontes (três). $\underline{A s}$ opiniões pessoais reforçaram a importância do material de apoio e das interações em grupo como os momentos mais importantes para o domínio da linguagem técnica.

\subsection{6 - Avaliação geral da experiência pelos alunos}

Em nível geral, as respostas dos alunos foram razoavelmente simétricas às avaliações feitas pelo professor (e apoiadas pelos observadores), com destaque para a intensidade da participação de todos os alunos, apesar de algumas queixas e desconfortos. Também reforçaram as observações do professor sobre a importância da interação, através de pequenos grupos. E justificaram a necessidade de produção de um material de apoio didático eficiente e consistente com a complexidade dos assuntos. Como balanço geral, foi solicitado que os alunos listassem pontos positivos e negativos da experiência.

\section{A - Alunos de graduação}

Entre os alunos de graduação, foram citados 16 pontos positivos, contra 7 pontos negativos, o que, em uma observação simplista, poderia indicar de imediato que a experiência foi bem sucedida. Entre os pontos positivos relacionados com os objetivos da experiência, estão: auto-aprendizado; trabalhos voltados à vida profissional; incentivo à busca de conhecimento; grande ligação entre a prática e a teoria; discussão de situações reais; execução de projetos; estudo dirigido é atividade útil.

Entre os pontos negativos, a reclamação de que algumas questões levantadas nas discussões do grupo não eram "fechadas" (aspas do aluno) pelo professor de maneira clara e objetiva. Um aluno informou que em alguns momentos teve dificuldade de resolver os problemas, considerando que nesses casos, seria necessária uma aula formal. Estas considerações remetem à natureza formal e expositiva predominante do ensino de engenharia, conforme já referido na avaliação do próprio professor. Remetem ainda às reflexões sobre os limites desejáveis para a utilização de experiências puramente construtivistas, em áreas como as engenharias, em que a exigência de conteúdos formais é muito grande. Seria impossível decidir, nesse momento, se as deficiências citadas são relacionadas com a existência de estruturas mentais já formadas pelo ensino de engenharia, que indisponibilizam o aluno à aceitação de um aprendizado autônomo, ou se realmente é necessário que cursos dessas áreas tenham sejam suficientemente flexíveis para poder ofertar também aulas formais, além de propostas construtivistas.

Dois alunos citaram que a integração entre alunos de graduação e mestrado não foi produtiva, porque os interesses são diferenciados.

\section{B - Alunos de mestrado}

Entre os mestrandos, o desequilíbrio numérico também é evidente à primeira vista: há 23 pontos positivos e 13 negativos. Entre os primeiros (pontos de mestrado), sete se 
referiram à qualidade do material de multimídia; sete relacionaram aspectos ligados à prática profissional; três enfocaram o estímulo ao auto-aprendizado e à independência em relação ao professor; e os demais se diluíram em itens relacionados à convivência agradável com o professor, à integração com o grupo, à versatilidade das aulas e outros.

Entre os pontos negativos, houve cinco opiniões relacionadas com a situação de aula não-convencional, ou seja, a mesma queixa relativa à falta de aulas expositivas, já comentadas. As outras opiniões foram relacionadas a questões gerenciais, como horário, falta de aulas práticas e outras.

\section{9 - Conclusões}

A experiência realizada na Escola de Engenharia da UFRGS procurou levantar elementos de compreensão sobre os fundamentos teóricos e as possibilidades práticas de aplicação do modelo construtivista para alunos do último ano de graduação e também de mestrado integrados na disciplina Investigação Geotécnica. Muito mais do que conclusões definitivas, a experiência permitiu refletir sobre as possibilidades de apropriação dos conceitos teóricos de Jean Piaget e das interpretações desses conceitos na formulação de um modelo pedagógico focado no aluno e na sua participação ativa na construção de seu próprio conhecimento. Cabe ressaltar que inúmeros artigos de professores e pesquisadores do ensino de Engenharia têm divulgado as vantagens desse modelo em relação ao ensino convencional, baseado em aulas expositivas.

Ao longo do tempo em que a experiência foi realizada, foram debatidas as observações práticas. Ao final da experiência, concluiu-se que:

a) o ensino de Engenharia tem especificidades que precisam ser resguardadas no planejamento de atividades didático-pedagógicas, relacionadas à complexidade dos conteúdos, os quais vêm sendo estruturados ao longo de muito tempo, sendo impraticável abrir mão de situações de exposição de conteúdos, de forma organizada e estruturada;

b) é necessário incorporar (ou em alguns casos consolidar) à prática pedagógica de Engenharia atividades de natureza construtivista, de forma a garantir a consolidação dos conhecimentos abordados através de iniciativas individuais.

c) a apresentação dos conteúdos pode e deve ser feita de forma múltipla e complementar, ora apoiada sobre a exposição do professor, ora em material didático de boa qualidade, incluindo livros e múltiplas mídias eletrônicas, incluindo vídeos e Internet;

d) é possível basear a apresentação de conteúdos, pelo professor, em estratégias dialogadas, como por exemplo na forma de perguntas em que os alunos vão desenvolvendo por si mesmos os raciocínios necessários à compreensão dos conteúdos, ou na forma de relato de casos, nos quais os alunos podem identificar os raciocínios necessários;

e) é necessário estabelecer estratégias de ensino integradoras de múltiplos domínios e conteúdos, como é o caso da realização de projetos, que sintetiza a própria atividade prática da Engenharia;

f) é possível e necessário flexibilizar a noção de modelo pedagógico, seja ele construtivista ou positivista, uma vez que ambos os conjuntos de práticas 
pedagógicas contêm estímulos de natureza distintas, porém fundamentais à estruturação de competências, habilidades e abstrações necessárias ao aluno de Engenharia;

g) são necessárias pesquisas mais aprofundadas para melhor informar os professores dessa área a respeito das reais possibilidades de cada modelo, bem como da formulação de modelos especificamente voltados à necessidade do ensino de Engenharia, baseados em paradigmas cognitivos e no perfil desejável do aluno dessa área.

\section{Referências bibliográficas}

BAZZO, Walter Antonio. Ciência, tecnologia e sociedade e o contexto da educação tecnológica. Florianópolis: Ed. da UFSC, 1998.

BECKER, Fernando. Aprendizagem e ensino: contribuições da Epistemologia Genética. Formação do Engenheiro. Desafios da atuação docente, tendências curriculares e questões contemporâneas da educação tecnológica. Florianópolis, Ed. da UFSC, 1999.

LODER, Liane. Epistemologia versus pedagogia. O lócus do Professor de Engenharia. Programa de Pós-Graduação em Educação/UFRGS. Porto Alegre, 2002. Dissertação de Mestrado

MILITITSKY, J. O desafio de formar engenheiros como transformadores sociais. Editorial ao Suplemento Engenharia, encartado no jornal Gazeta Mercantil/RS de 17 de agosto de 1998.

MORAES, Roque. Construtivismo e Ensino de Ciências: reflexões epistemológicas e metodológicas. Porto Alegre, RS, Brasil. EDIPUCRGS, 2000.

PIAGET, J. Formação do símbolo na criança. Fondo de Cultura Econômica, México, D.F., 1986.

PIAGET, J. O nascimento da inteligência na criança. Rio de Janeiro, LIC Editora, 4a. ed., 1987.

PIAGET J. A construção do real na criança. São Paulo, Ed. Ática, 2001.

PIAGET, J. Biologia e Conhecimento. São Paulo, Ed. Vozes, 1973.

PIAGET, J. Ciências e Filosofia. In: Os Pensadores. São Paulo. Abril Cultural, 1983.

PIAGET, J. Psicologia e Epistemologia. Lisboa. Nova Enciclopédia, 1991. 
SCHNAID, F.; TIMM, M.I.; ZARO, M.A. \& FERREIRA F ${ }^{o}$, R.C.M. Multimídia e Ensino à Distância na Engenharia Civil - Disciplina de Investigação Geotécnica. In: Anais XXIX COBENGE. Porto Alegre, 2001.

SCHNAID, F; BARBOSA, F. e TIMM, M. I. O perfil do engenheiro ao longo da história. In: Anais XXVIII Congresso Brasileiro de Ensino de Engenharia, COBENGE. Porto Alegre, 2000.

ZARO, M. A., TIMM, M.I. LMM: Uma experiência pedagógica no ensino de instrumentação. In: Anais XXVII COBENGE. Natal, 1999. 